\title{
Seasonal patterns of gastrointestinal nematode infection in goats on two Lithuanian farms
}

Inga Stadaliené ${ }^{1}$, Johan Höglund ${ }^{2}$ and Saulius Petkevičius ${ }^{1 *}$

\begin{abstract}
Background: This study investigated seasonal changes in naturally acquired gastrointestinal nematode (GIN) infections on two Lithuanian goat farms with different parasite control practices.

Findings: On both farms, nematode faecal egg counts (FEC) and larval cultures were obtained from 15 adult and 10 young goats at bi-weekly intervals from April 2012 to April 2013. Goats on farm A were dewormed with ivermectin (0.3 mg/kg body weight) in October/November 2012, whereas the animals on farm B were left untreated. Thirteen young goats were slaughtered in August/November 2012 and April 2013 and worm burdens in the gastrointestinal tract were enumerated. In goats from both farms, Teladorsagia, Trichostrongylus, Oesophagostomum, Chabertia and Haemonchus were the dominant GIN genera. Herbage contamination with infective third-stage larvae $\left(L_{3}\right)$ peaked in July/August and resulted in high FEC in September/October. Parasitological examination at slaughter showed that Teladorsagia spp. and Haemonchus contortus survived the winter, both in the abomasal mucosa as adults and as early fourth-stage larvae $\left(E L_{4}\right)$. Deworming on farm A significantly reduced FEC, especially of $\mathrm{H}$. contortus, at the start of the grazing period compared with the untreated farm $B(P<0.05)$.

Conclusions: Goats were heavily infected with several GIN throughout the year. Strategic anthelmintic treatment during housing significantly reduced nematode egg output, in particular by H. contortus, at the start of the grazing season.
\end{abstract}

Keywords: Goats, Epidemiology, Arrested larvae, Teladorsagia, Haemonchus contortus

\section{Findings}

The risk of gastrointestinal nematode (GIN) infections in small ruminants is determined by factors such as climate, level of nutrition, stocking density and management. During the past two years, the goat population in Lithuania has increased by $28 \%$, to 9,300 animals in 2014 [1]. This has led to increased stocking rates on pasture, with associated productivity losses from GIN infections [2].

The effects of GIN are predicted to become more severe due to global warming [3,4]. One such example of the possible influence of ongoing climate change is the increased infection levels of Haemonchus contortus observed in Scandinavia [5,6]. However, as long as anthelmintics are effective, strategic treatments reduce parasite pasture contamination and lower the exposure to GIN

\footnotetext{
* Correspondence: petkevicius@lva.lt

'Department of Infectious Diseases, Veterinary Academy, Lithuanian University of Health Sciences, Tilžès 18, LT-47181 Kaunas, Lithuania Full list of author information is available at the end of the article
}

associated with increased milk yields in goats [7]. Deworming during housing is the most commonly used control practice against GIN in Norway [8] and it has been shown that it significantly reduces faecal egg counts (FEC) in the next grazing season [9]. Reduced FEC at the start of the grazing period prevents pasture contamination, especially by $H$. contortus since its freeliving stages are sensitive to sub-zero temperatures $[3,10]$. $H$. contortus mainly survives the winter inside the host, as arrested forms in the abomasal mucosa [11]. Previous studies on GIN in Lithuanian sheep and cattle have shown high levels of larval inhibition $[12,13]$. In contrast, information from Lithuanian goats has hitherto been lacking.

This study investigated seasonal fluctuations in GIN on two goat farms in central Lithuania, of which farm A was treated with anthelmintics and farm B was left untreated. Both farms had White Shorthaired Goats. The study took place between April 2012 and April 2013 and the grazing period was from late April until late 
October. During housing, the animals were fed hay/haylage, vegetables (sugar-beet, carrots) and grain. The kidding period on both farms started in late January and lasted until late February. Kids were weaned after approximately 3 months. On farm A, the kids grazed separately from the adult goats until October in a paddock with $500 \mathrm{~kg} / \mathrm{ha}$ (adults $320 \mathrm{~kg} / \mathrm{ha}$ ), whereas on farm B they grazed in the same paddock $(235 \mathrm{~kg} / \mathrm{ha})$.

Mean monthly temperature was similar and peaked $\left(19.6^{\circ} \mathrm{C}\right)$ in July. Compared with the long-term average (1961-1990), the temperature on both farms was on an average $1-3^{\circ} \mathrm{C}$ higher during grazing. Winter temperature varied on average between $-1.0^{\circ} \mathrm{C}$ and $-6.7^{\circ} \mathrm{C}$. The highest level of rainfall was observed in June/July (89.7$138.6 \mathrm{~mm})$.

Anthelmintics had not been used on either farm for 4 months prior to the start of the trial. On farm A, the young goats received injectable ivermectin (Ivomec ${ }^{\circ} 1 \%$, $0.3 \mathrm{mg}$ per $\mathrm{kg}$ body weight) in early October, while the adults were dewormed in late November. On farm B, all goats were left untreated throughout the study.

The work was performed in compliance with Lithuanian animal welfare regulations (No. B1-866, 2012; No. XI-2271, 2012) and was approved by the Lithuanian Committee of Veterinary Medicine and Zootechnics Sciences (Protocol No.07/2010).

Animals in each flock were selected by stratified random sampling by sex (female) and body weight, and categorised as young goats $(<1$ year; $\mathrm{n}=10)$ or adults ( $>1$ year; $\mathrm{n}=15$ ). Faeces samples were collected directly from the rectum at bi-weekly intervals. FEC were performed using a modified McMaster technique with minimum detection level of 20 nematode eggs per gram (EPG) faeces [14]. Furthermore, $1 \mathrm{~g}$ samples of faeces from each animal in the same grazing group were pooled and faecal cultures were prepared to obtain infective third-stage larvae $\left(\mathrm{L}_{3}\right)$ [15]. Identification to genus or species level was based on morphological keys [16]. In addition, triplicate $(\approx 400 \mathrm{~g})$ samples of herbage were collected between May and November 2013 from each of the paddocks used by the goats on both farms, for determination of number of $L_{3}$ [17]. Furthermore, six young females from farm A and seven from farm B were sent to the local slaughter-house for slaughtering between 25 August and 25 April 2013 and the viscera of the goats were collected for parasitological investigation. The abomasa and small- and large intestines were opened for enumeration and identification of GIN, while the abomasal mucosa was digested and examined for inhibited stages according to Grønvold [18]. Nematodes were collected and identified to species or genus [19]. Statistical comparisons of FEC between farms were performed using Repeated Measures Analysis of Variance (ANOVA) analysis in BMI SPSS Statistics 21 version. Prevalence of nematode infections in the gastrointestinal (GI) tract and standard 95\% confidence intervals (CI) were also calculated. Worm burdens on the two farms were compared using one-way ANOVA, with $P<0.05$ as statistically significant.

Pasture contamination was low $\left(88-499 \mathrm{~L}_{3} / \mathrm{kg}\right)$ at the start of the study and remained low until late June (Figure 1). In contrast, from late June, $\mathrm{L}_{3}$ numbers in herbage began to increase, with a peak in late July, in the paddock used by adult goats on farm $A$ and in the common paddock on farm B. Two weeks later, in August, there was a peak in $\mathrm{L}_{3}$ pasture contamination in the paddock grazed by the young goats on farm A. These peaks in $\mathrm{L}_{3}$ between July and August represented the first wave of pasture contamination, and must have originated from nematode eggs shed with the faeces of adult goats between April and June (Figure 2A). These parasite eggs most likely originated from adult worms that had resumed their development from arrested larvae in the mucosa of adult goats. This infection wave resulted in subsequent peaks of parasite eggs shed, which were observed in both adult flocks in September. However, the FEC was much higher on farm A, probably as a result of the high stocking density. The FEC in young goats on both farms peaked and reached its highest levels in September/October 2012 (Figure 2B). However, again FEC

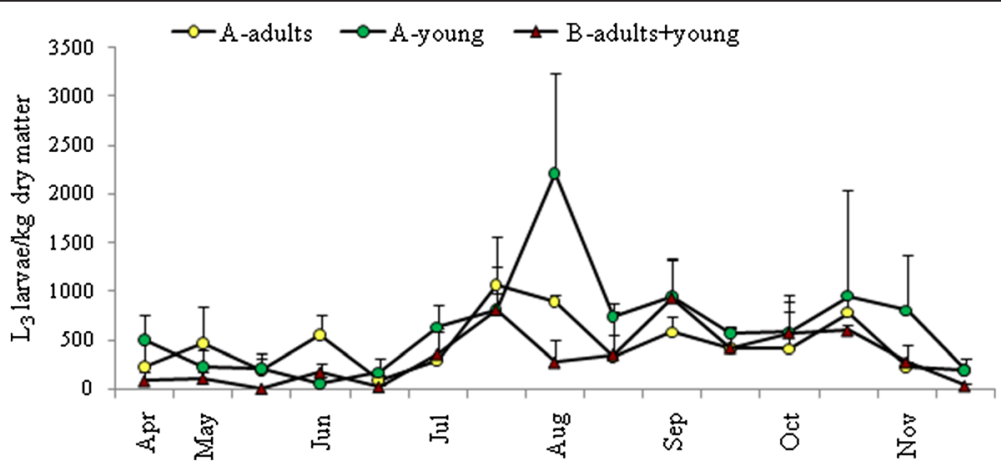

Figure 1 Mean number of $L_{3}$ stage larvae per kg dry matter of grass on farms $A$ and $B$. 
A
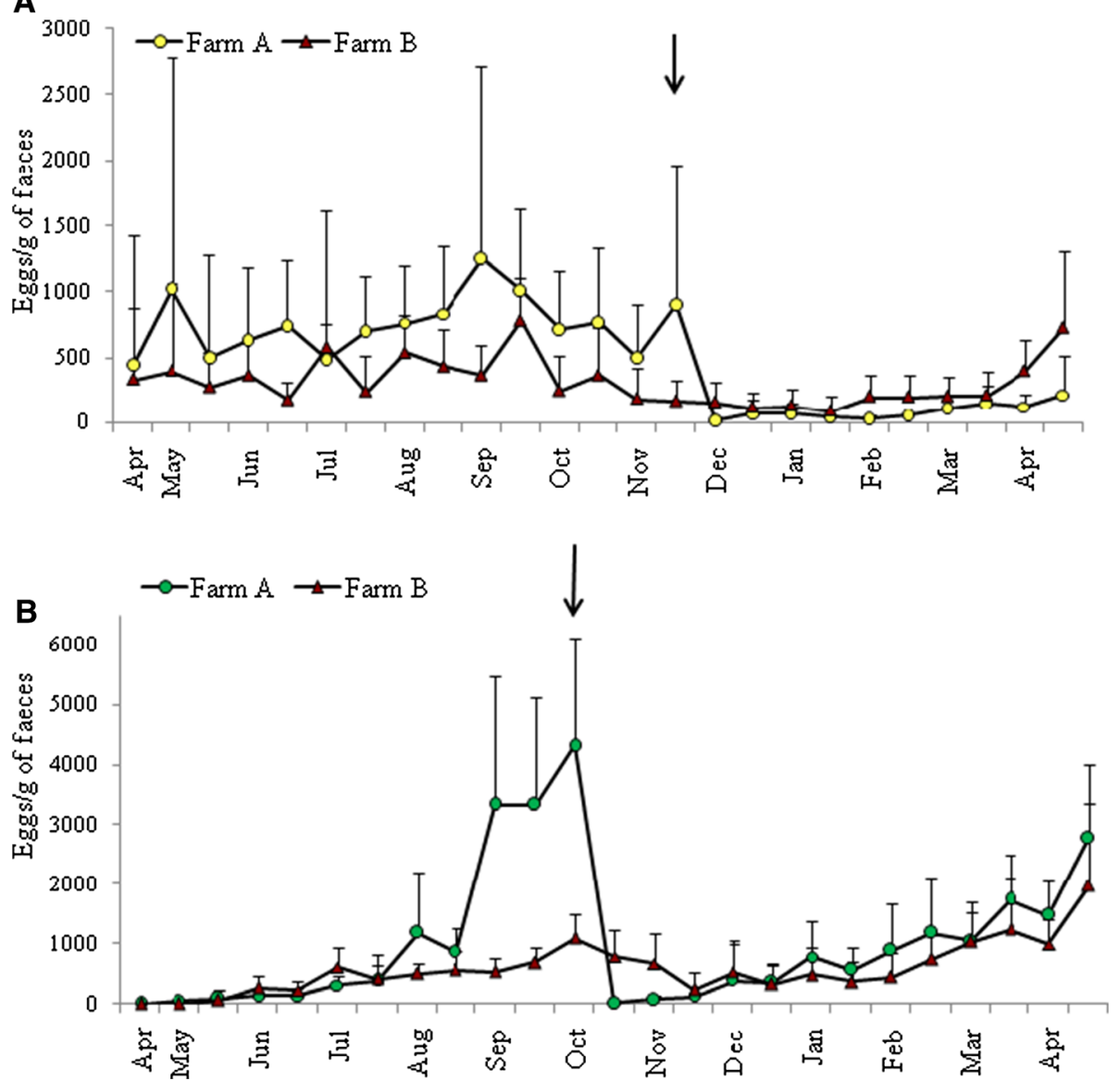

Figure 2 Mean number of strongyle nematode eggs per gram faeces (EPG) in A) adult dairy goats and B) young goats on anthelmintictreated farm $\mathbf{A}$ and untreated farm $\mathbf{B}$. Arrows indicate time of treatment on farm $\mathbf{A}$.

was significantly higher $(P<0.001)$ on farm $\mathrm{A}$, probably as a result of the higher grazing intensity compared with farm B. All young goats on farm A were dewormed in October 2012. Although this decreased FEC, it did not prevent the spring rise in FEC, which was observed towards the end of April in the next year. The second wave of pasture contamination in October resulted in re-infection and a source of arrested larvae, creating an overwintering nematode population in the GI tract. During the housing period (November-April), FEC in the young goats gradually increased, followed by a marked rise by the end of April 2013 on both farms.

Teladorsagia dominated both in the samples from pasture $(42-100 \%)$ and in faecal cultures $(42 \%)$ on both farms, confirming results from other European countries [6,20-22]. In addition, $\mathrm{L}_{3}$ of Trichostrongylus (26\%),

Table 1 Mean number of worms and proportion (\% of total) of Haemonchus contortus and Teladorsagia sp. development stages in abomasum of young goats at slaughter

\begin{tabular}{|c|c|c|c|c|c|c|c|c|}
\hline \multirow[b]{2}{*}{ Date } & \multicolumn{4}{|c|}{ H. contortus } & \multicolumn{4}{|c|}{ Teladorsagia $^{\mathrm{a}}$} \\
\hline & Adult & $\mathrm{DL}_{4}$ & $\mathrm{EL}_{4}$ & Mean total & Adult & $\mathrm{DL}_{4}$ & $\mathrm{EL}_{4}$ & Mean total \\
\hline 25 Aug & 134 (20\%) & $54(6 \%)$ & 553 (74\%) & 741 & 4949 (83\%) & $154(3 \%)$ & 908 (14\%) & 6011 \\
\hline 14 Sep & $71(1 \%)$ & 0 & 8325 (99\%) & 8396 & $10346(66 \%)$ & 451 (3\%) & $4500(31 \%)$ & 15297 \\
\hline $08 \mathrm{Oct}$ & 300 (22\%) & $225(25 \%)$ & 251 (53\%) & 776 & 4522 (93\%) & 111 (2\%) & 183 (4\%) & 4816 \\
\hline 29 Oct & 0 & $24(1 \%)$ & 3656 (99\%) & 3680 & $5633(86 \%)$ & $74(1 \%)$ & 826 (13\%) & 6533 \\
\hline $29 \mathrm{Nov}$ & 239 (12\%) & 0 & $2342(88 \%)$ & 2581 & 7196 (88\%) & $12(1 \%)$ & $1026(11 \%)$ & 8234 \\
\hline $25 \mathrm{Apr}$ & 485 (97\%) & 0 & $14(3 \%)$ & 499 & 1083 (96\%) & 0 & $46(4 \%)$ & 1129 \\
\hline
\end{tabular}

${ }^{\mathrm{a}}$ Te. circumcincta and Te. trifurcata. 
Table 2 Mean number of worms and proportion (\% of total) of Trichostrongylus and Oesophagostomum/Chabertia development stages in the small and large intestines of young goats at slaughter

\begin{tabular}{|c|c|c|c|c|c|c|}
\hline \multirow[b]{2}{*}{ Date } & \multicolumn{3}{|c|}{ Trichostrongylus $^{\mathrm{a}}$} & \multicolumn{3}{|c|}{ Oesophagostomum/Chabertia ${ }^{b}$} \\
\hline & Adult & Developing & Mean total & Adult & Developing & Mean total \\
\hline 25 Aug & $2851(75 \%)$ & 1067 (25\%) & 3919 & $163(20 \%)$ & $687(80 \%)$ & 850 \\
\hline 14 Sep & $15005(91 \%)$ & $1000(9 \%)$ & 16305 & $515(83 \%)$ & $130(17 \%)$ & 645 \\
\hline $08 \mathrm{Oct}$ & $35174(87 \%)$ & $4073(13 \%)$ & 39247 & $78(48 \%)$ & $98(52 \%)$ & 176 \\
\hline 29 Oct & $4697(98 \%)$ & $87(2 \%)$ & 4784 & $235(92 \%)$ & $20(8 \%)$ & 255 \\
\hline $29 \mathrm{Nov}$ & $4962(93 \%)$ & 419 (7\%) & 5381 & $105(78 \%)$ & $30(22 \%)$ & 135 \\
\hline $25 \mathrm{Apr}$ & $8775(100 \%)$ & 0 & 8775 & $240(100 \%)$ & 0 & 240 \\
\hline
\end{tabular}

${ }^{\mathrm{a}}$ T. capricola, T. colubriformis and T. vitrinus.

${ }^{\mathrm{b} O}$. venulosum and C. ovina.

Oesophagostomum (13\%), Chabertia (11\%) and H. contortus $(8 \%)$ were identified in the faecal cultures. Interestingly, $H$. contortus was only observed during the grazing period (May-October) on farm A ( $3-35 \%$ of the total nematode population) and farm B $(8-31 \%)$. In addition, $H$. contortus was detected in faecal cultures of young goats from late June and increased between August and October. This was particularly the case on farm A, where $H$. contortus comprised $16-21 \%$ of the total nematode population. Similarly, pasture contamination with $H$. contortus larvae was first detected in mid-May, but was highest between August and October $(9-50 \%)$. This is in agreement with Swedish findings on GIN in sheep [10].

In the GI tract, the following species were identified in the abomasum: Teladorsagia circumcincta $52 \%$ (95\% CI: $42-62 \%)$, Te. trifurcata 34\% (95\% CI: $23-47 \%)$, Trichostrongylus axei $7 \%$ (95\% CI: $3-12 \%)$ and $H$. contortus $7 \%$ (95\% CI: $1-12 \%)$. In the small intestine, the species identified were: $T$. capricola $45 \%$ (95\% CI: $34-$ 56\%), T. colubriformis 43\% (95\% CI: $32-52 \%$ ), T. vitrinus 11\% (95\% CI: 7 - 16\%) and Strongyloides papillosus $1 \%$ (95\% CI: $0-2 \%)$. The species found in the large intestine were: Oesophagostomum venulosum 65\% (95\% CI: $52-80 \%)$, Chabertia ovina 34\% (95\% CI: $19-49 \%)$ and Trichuris ovis 1\% (95\% CI: 0 - 3\%). For Teladorsagia spp., adult worms dominated in the abomasum, while for $H$. contortus early fourth-stage larvae $\left(\mathrm{EL}_{4}\right)$ dominated (Table 1). Arrested H. contortus were mainly observed between August and November (53-99\%), but to a lesser extent also in early April (Table 1 ). Developing larvae $\left(\mathrm{DL}_{4}\right)$ of $H$. contortus were found until late October and of Teladorsagia spp. until late November. Subsequent examinations in April showed that $\geq 95 \%$ of the total worm burdens were adults, with only a low percentage of $H$. contortus (3\%) and Teladorsagia (4\%) in the $\mathrm{EL}_{4}$ stage. The $\mathrm{L}_{3}$ of $H$. contortus ingested in autumn obviously did not start to develop until early spring, resulting in decreased $\mathrm{L}_{4}$ development and adult worm reproduction. Tracer tests on lambs in Sweden have shown that arrest of $H$. contortus takes place mainly from July and that $T$. circumcincta comprises a lower percentage of the increasing numbers of nematodes during the grazing season [11]. The significantly higher numbers of adults than of developing stages $(P<0.05)$ of Trichostrongylus spp., O. venulosum and $C$. ovina observed in the tracers indicate that these nematodes survived the winter within the host as adults (Table 2). Deworming of adult goats at the end of November on farm A significantly reduced FEC at the start of grazing compared with on the untreated farm B $(P<0.05)$. After deworming on farm $\mathrm{A}, H$. contortus $\mathrm{L}_{3}$ were not observed in faecal cultures until March 2013 and in April comprised only $2-3 \%$. The corresponding proportion of this parasite in faeces of goats on farm B was $1-4 \%$ during housing, but in April of the next year 38\% of the cultured $\mathrm{L}_{3}$ were $H$. contortus. Thus, deworming of adults and young goats in late autumn reduced the $H$. contortus population considerably in early spring and thereby prevented pasture contamination. The high percentage of $H$. contortus (31-53\%) in faecal cultures of adult and young goats shows that development of this parasite resumed from April-May. If deworming is not performed in late autumn, it could be implemented in spring before turn-out [5].

In conclusion, the Lithuanian goats studied here were infected with a mixture of GIN, in particular Teladorsagia spp. but also several other genera, including the more pathogenic $H$. contortus. FEC fluctuated in relation to the level of herbage contamination, which varied according to season on both farms. Strategic anthelmintic treatment of adult goats in November significantly reduced FEC, especially of $H$. contortus.

\section{Competing interests}

The authors declare that they have no competing interests.

\section{Authors' contributions}

IS collected and analysed the data, performed the literature review and drafted the manuscript. SP generated the study design, coordinated the experiment and took part in the writing. $\mathrm{JH}$ participated in planning and preparing the study design and finalised the manuscript. All authors read and approved the final draft of the manuscript. 


\section{Acknowledgements}

The authors thank the owners of farms $A$ and $B$ for their participation in the study, veterinary students of the Veterinary Academy, Lithuanian University of Health Sciences, for their help in collection of samples and Dr. Mary McAfee for language editing.

\section{Author details}

${ }^{1}$ Department of Infectious Diseases, Veterinary Academy, Lithuanian University of Health Sciences, Tilžès 18, LT-47181 Kaunas, Lithuania. ${ }^{2}$ Department of Biomedical Sciences and Veterinary Public Health, Swedish University of Agricultural Sciences, P.O. Box 7028, SE-750 07 Uppsala, Sweden.

Received: 21 July 2014 Accepted: 4 March 2015

Published online: 19 March 2015

\section{References}

1. Agricultural Information and Rural Development Centre (AIRDC). Official Statistics, Lithuania [http://www.vic.lt/?mid=288]

2. Thamsborg SM, Jørgensen RJ, Ranvig H, Bartlett P, Waller PJ, Nansen P. The performance of grazing sheep in relation to stocking rate and exposure to nematode infections. Livest Prod Sci. 1998;53:265-77.

3. Van Dijk J, Sargison ND, Kenyon F, Skuce PJ. Climate change and infectious disease: helminthological challenges to farmed ruminants in temperate regions. Animal. 2010;4:377-92.

4. Morgan ER, Van Dijk J. Climate and the epidemiology of gastrointestinal nematode infections of sheep in Europe. Vet Parasitol. 2012;189:8-14.

5. Lindqvist $\AA$, Ljungström B-L, Nilsson O, Waller PJ. The dynamics, prevalence and impact of nematode infections in organically raised sheep in Sweden. Acta Vet Scand. 2001:42:377-89.

6. Domke AVM, Chartier C, Gjerde B, Leine N, Vatn S, Stuen S. Prevalence of gastrointestinal helminths, lungworms and liver fluke in sheep and goats in Norway. Vet Parasitol. 2013;194:40-8.

7. Cringoli G, Veneziano V, Jackson F, Vercruysse J, Greer AW, Fedele V, et al. Effects of strategic anthelmintic treatments on the milk production of dairy sheep naturally infected by gastrointestinal strongyles. Vet Parasitol. 2008:156:340-5.

8. Domke AVM, Chartier C, Gjerde B, Leine N, Vatn S, Østerås O, et al. Worm control practice against gastro-intestinal parasites in Norwegian sheep and goat flocks. Acta Vet Scand. 2011;53:29.

9. Waller PJ, Rydzik A, Ljungström BL, Törnquist M. Towards the eradication of Haemonchu contortus from sheep flocks in Sweden. Vet Parasitol. 2006;136:367-72.

10. Troell $K$, Waller $P$, Höglund J. The development and overwintering survival of free-living larvae of Haemonchuscontortus in Sweden. J Helminthol. 2005:79:373-9.

11. Waller PJ, Rudby-Martin $L$, Ljungström BL, Rydzik $A$. The epidemiology of abomasal nematodes of sheep in Sweden, with particular reference to overwinter survival strategies. Vet Parasitol. 2004;122:207-20.

12. Šarkūnas M, Paulikas V, Šarkūnas V. Avių strongilatozès. Vet Med Zoot. 1996:23:135-9.

13. Šarkūnas M, Malakauskas A, Paulikas V, Nansen P, Hansen JW. Natural trichostrongylid exposure of calves in Lithuania: effect of midsummer move to clean pasture with special reference to inhibited development in the early $L_{4}$ stage trichostrongylid larvae. Helminthologia. 1998;35:35-72.

14. Roepstorff A, Nansen P. Epidemiology, diagnosis and control of helminth parasites of swine. In: FAO Animal Health Manual. Volume 3. Rome: FAO; 1998. p. 161

15. Henriksen SA, Korsholm $\mathrm{H}$. The method for culture and recovery of gastrointestinal strongyle larvae. Nord Vet Med. 1983;35:429-30.

16. Van Wyk JA, Cabaret J, Michael LM. Morphological identification of nematode larvae of small ruminants and cattle simplified. Vet Parasitol. 2004;119:277-306.

17. Fernandez AS, Šarkūnas M, Roepstorff A. Survival of infective Ostertagia ostertagi larvae on pasture plots under different simulated grazing conditions. Vet Parasitol. 2001;96:291-9.

18. Grønvold J. Laboratory diagnoses of helminths. Common routine methods used in Denmark. In: Nansen P, Grønvold J, Bjørn H, editors. Seminars on Parasitic Problems in Farm Animals Related to Fodder Production and Management. Tartu. Estonia: Proceedings of the Estonian Academy of Sciences; 1991. p. 54-5.
19. Barth D, Visser M. Magen-Darm-nematoden des Rindes. Diagnostischer Atlas. Stuttgart: Ferdinand Enke Verlag; 1991. p. 7-97.

20. Chartier C, Reche B. Gastrointestinal helminths and lungworms of French dairy goats: prevalence and geographical distribution in Poitou-Charentes. Vet Res Comm. 1992;16:327-35.

21. Valcarcel F, Romero GC. Prevalence and seasonal pattern of caprine trichostrongyles in a dry area of Central Spain. J Vet Med Series B. 1999:46:673-81.

22. Papadopoulos E, Arsenos G, Sotiraki S, Deligiannis C, Lainas T, Zygoyiannis D. The epizootiology of gastrointestinal nematode parasites in Greek dairy breeds of sheep and goats. Small Rumin Res. 2003;47:193-202.

\section{Submit your next manuscript to BioMed Central and take full advantage of:}

- Convenient online submission

- Thorough peer review

- No space constraints or color figure charges

- Immediate publication on acceptance

- Inclusion in PubMed, CAS, Scopus and Google Scholar

- Research which is freely available for redistribution 